\title{
PENGARUH SERVICE ENVIRONMENT, CUSTOMER KNOWLEDGE, DAN CUSTOMER RELATION MANAGEMENT TERHADAP SERVICE QUALITY DAN DAMPAKNYA TERHADAP BRAND EQUITY
}

\author{
Verry Wijaya \\ Program Studi Magister Manajemen Universitas Tarumanagara \\ verrywijaya12@gmail.com \\ Chairy \\ Program Studi Magister Manajemen Universitas Tarumanagara
}

\begin{abstract}
This study aims to determine the effect of service environment, customer knowledge, and customer relations management on service quality and its impact on brand equity at PT. XYZ. In addition, it can provide input to the company regarding the brand equity of the private brand of PT. XYZ and can help companies in designing the right and effective marketing strategy planning so that the company can survive in the retail world competition in the modern market. This study uses qualitative methods and is included in survey research. The data to be taken is primary data obtained through interviews with visitors to PT. XYZ uses a questionnaire. The population in this study is the consumer respondents in one of the outlets PT. XYZ in Jakarta. The sampling technique is probability sampling with the sample criteria used are respondents from consumers. Because the population in the study is unknown, the number of samples used in this study is 100-150 respondents where the number of respondents obtained the number of indicators in the research questionnaire (Hair et.al 2016, p.102). Analysis of the data in this study using this type of analysis Structure Equation Model (SEM) with the help of the program AMOS 18. The results showed that the service environment had a positive relationship but did not have a significant effect on service quality..
\end{abstract}

Abstrak : Penelitian ini bertujuan untuk mengetahui pengaruh lingkungan layanan, pengetahuan pelanggan, dan manajemen hubungan pelanggan terhadap kualitas layanan dan dampaknya terhadap ekuitas merek di PT. XYZ. Selain itu, dapat memberikan masukan kepada perusahaan mengenai ekuitas merek dari merek pribadi PT. XYZ dan dapat membantu perusahaan dalam merancang perencanaan strategi pemasaran yang tepat dan efektif sehingga perusahaan dapat bertahan dalam persaingan dunia ritel di pasar modern. Penelitian ini menggunakan metode kualitatif dan termasuk dalam penelitian survei. Data yang akan diambil adalah data primer yang diperoleh melalui wawancara dengan pengunjung ke PT. XYZ menggunakan kuesioner. Populasi dalam penelitian ini adalah responden konsumen di salah satu outlet PT. XYZ di Jakarta. Teknik pengambilan sampel adalah probability sampling dengan kriteria sampel yang digunakan adalah responden dari konsumen. Karena populasi dalam penelitian ini tidak diketahui, jumlah sampel yang digunakan dalam penelitian ini adalah 100-150 responden di mana jumlah responden memperoleh jumlah indikator dalam kuesioner penelitian (Hair et.al 2016, p.102). Analisis data dalam penelitian ini menggunakan jenis analisis Structure Equation Model (SEM) dengan bantuan program AMOS 18.

Keywords: service environment, customer knowledge, customer relationship management, service quality and brand equity 


\section{PENDAHULUAN}

Trend perkembangan dunia retail saat ini menunjukkan pertumbuhan yang sangat pesat pada pasar modern, gejala ini menyebar ke seluruh dunia termasuk di Indonesia. Dengan adanya perkembangan dunia retail ini pasar tradisional di Indonesia semakin terancam dalam usahanya, karena pertumbuhan pasar modern semakin besar seiring waktunya (Tempo.com).

Seiring dengan perkembangan pasar modern di Indonesia maka para retailer akan bersaing lebih keras lagi untuk mempertahankan keunggulan bersaingnya. Para retailer melakukan operasi dengan membentuk organisasi yang lebih efektif, efisien dan untuk mempertahankan pasarnya retailer beroperasi dengan gross margin yang lebih rendah, biaya operasional yang rendah, inventori yang cukup agar perputaran barang dapat lebih cepat (Marliana, 2018).

Merek merupakan bagian penting dari bisnis dan aset perusahaan, banyak bisnis tertarik untuk mempelajari cara membangun merek yang sukses. Strategi untuk menciptakan ekuitas merek sebagai strategi kompetitif lain dapat membantu berbagai bisnis dan organisasi dalam mencapai tujuan kinerja (Majid, Zahra, dan Azade, 2016). Salah satu persyaratan untuk menciptakan merek yang kuat adalah mengenali faktor-faktor penyebab ekuitas merek (Rousta dan Madani, 2010). Menurut Edward dan Wang (2015) salah satu faktor utama yang membantu menciptakan merek yang kuat adalah investasi dan meningkatkan kualitas layanan. Hasil penelitian Majid, Zahra, dan Azade (2016) menunjukkan bahwa kualitas pelayanan memiliki dampak positif dan signifikan terhadap ekuitas merek. Hasil penelitian Hye, Lee and Kim (2012) menunjukkan bahwa environment berpengaruh terhadap service quality.

Gibbert et al. (2002) mencatat bahwa perusahaan harus hati-hati mengamati, berinteraksi dan membuat dialog dengan pelanggan mereka untuk memperoleh pengetahuan pelanggan sehingga mereka dapat memberikan layanan yang disesuaikan dan mempertahankan hubungan jangka panjang (Nazeri and Tajdin, 2017). Selain itu, Customer relationship management (CRM) merupakan strategi tentang bagaimana mengoptimalkan profitbilitas melalui hubungan baik dengan pelanggan dan penciptaan kepuasan pelanggan (Sait, 2018). Berdasarkan uraian di atas, maka peneliti tertarik untuk melakukan penelitian tentang "Pengaruh Service Environment, Customer Knowledge, Dan Customer Relation Management Terhadap Service Quality Dan Dampaknya Terhadap Brand Equity".

\section{KERANGKA PEMIKIRAN TEORITIS DAN PERUMUSAN HIPOTESIS}

\section{Pengertian Pemasaran}

Menurut Hartono et.al (2012) pemasaran adalah salah satu kegiatan dalam perekonomian yang membantu dalam menciptakan nilai ekonomi. Nilai ekonomi itu sendiri menentukan harga barang dan jasa. Faktor penting dalam menciptakan nilai tersebut adalah produksi, pemasaran, dan konsumsi. Pemasaran menjadi penghubung antara kegiatan produksi dan konsumsi.

\section{Pengertian Brand (Merek)}

Pemahaman akan Brand menjadi hal yang sangat penting, karena pemasaran yang berawal dari pengertian kebutuhan konsumen secara fungsional dan psikologikal dikemas dalam sebuah Brand (merek), dan dikonsumsikan ke pasar. Berikut ini adalah beberapa definisi tentang merek menurut (Kotler, 2009:332) yakni, Brand (merek) merupakan nama, istilah, tanda, symbol atau rancangan, atau kombinasi dari semuanya, yang dimaksudkan 
untuk mengidentifikasi barang atau jasa atau kelompok penjual dan untuk mendiferensiasikan (membedakan) dari barang atau jasa pesaing.

\section{Pengertian Private Label}

Hadi (2009) dalam Allegro (2015) menyatakan berdasarkan definisi dari para ahli, bahwa yang dimaksud dengan private label brands adalah merek utama pada suatu toko sebagai identitas perusahaan dan kualitas, serta dilihat sebagai sumber penting dari profitabilitas perusahaan.

\section{Services Environment}

Service Environment memiliki peran penting dalam pemberian pelayanan karena lingkungan dapat memberikan reaksi emosional yang menyenangkan, sekaligus memperkuat pelanggan. Persepsi dan perilaku dalam lingkungan tertentu adalah hasil emosional bagian keadaan yang diciptakan oleh lingkungan. Secara khusus ransangan lingkungan mempengaruhi emosi. Service environment mencakup sejumlah dimensi diklasifikasikan menjadi dua karakteristik (Rahayu: 2011:118): 1) Lingkungan internal; adalah budaya organisasi dan filsafat yang menjadi dasarnya layanan pendidikan. Ini termasuk yayasan dan substansi akademik, akademik kebebasan, dan keinginan untuk menemukan hal-hal baru terkait dengan akademisi. 2) Lingkungan luar; adalah lingkungan fisik di mana layanan pendidikan diterapkan. Lingkungan fisik meliputi; infrastruktur (Parkir, membangun ceramah, fasilitas lab, ruang diskusi, perpustakaan, dll).

\section{Customer Knowledge}

Menurut Abdis et.al (2015) knowledge adalah dasar-dasar informasi yang terletak dalam pikiran manusia yang didapat nya dari penglihatan, pengalaman dan prosedur yang telah dipertimbangkan keabsahannya melalui proses sebab akibat sehingga bermanfaat dalam melakukan analisa, memutuskan, mengambil keputusan dalam berbagai kondisi kehidupan.

\section{Customer Relationship Management}

Menurut Buttle (2006) dalam Marshellina dan Prabowo (2013) Customer Relationship Management adalah pendekatan strategi manajemen dalam upaya menciptakan, mengembangkan, dan mewujudkan hubungan yang saling menguntungkan dengan pelanggan dalam jangka panjang, khususnya terhadap pelanggan potensial, dalam upaya memaksimalkan costumer value (nilai pelanggan) dan corporate profitability

\section{Service Quality}

Definisi kualitas pelayanan berpusat pada upaya pemenuhan kebutuhan dan keinginan pelanggan serta ketepatan penyampaiannya untuk mengimbangi harapan pelanggan. Menurut Tjiptono (2008) dalam Angkow et.al (2016), kualitas pelayanan adalah tingkat keunggulan yang diharapkan dan pengendalian atas tingkat keunggulan tersebut untuk memenuhi keinginan pelanggan. Menurut Martin (2001) dalam Iskandar dan Sugiharto (2013), kualitas layanan adalah suatu kemampuan untuk memenuhi kebutuhan internal dan ekstemal pelanggan secara konsisten sesuai prosedur.

\section{Brand Equity}

Menurut Majid, Zahra dan Azade (2016), Ekuitas merek didefinisikan sebagai penilaian subjektif pelanggan dan evaluasi tidak berwujud dari sebuah merek. Ekuitas merek adalah nilai yang diciptakan dengan meningkatkan efektivitas kegiatan pemasaran, menciptakan tingkat preferensi merek yang lebih tinggi, keinginan untuk membeli dan kenaikan pangsa pasar perusahaan. Selain itu, ekuitas merek berbasis konsumen sebagai pengakuan dampak 
merek Berkaitan dengan konsumen terhadap reaksi konsumen terhadap komplek perusahaan strategi pemasaran. Keempat dimensi ekuitas merek yang diberikan oleh Aaker (1991) adalah sebagai berikut: persepsi kualitas, brand awareness, brand Asosiasi, loyalitas merek.

\section{Model Penelitian}

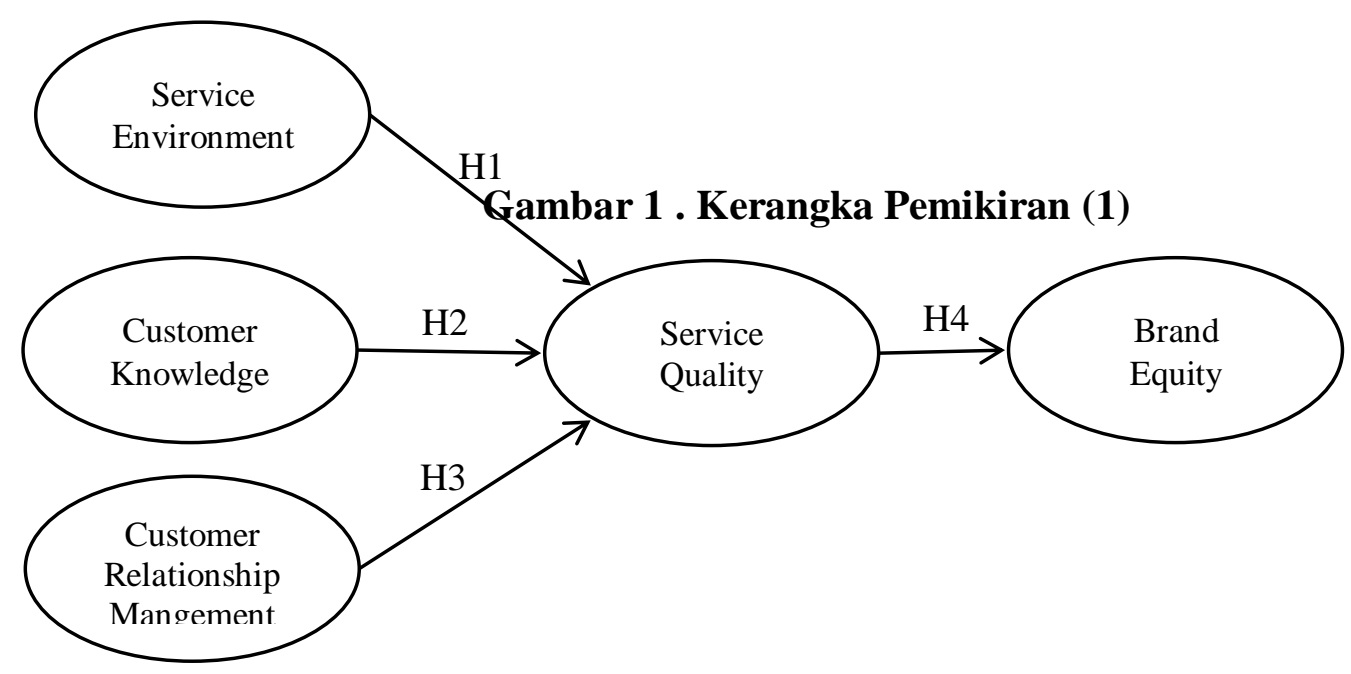

\section{Hipotesis Penelitian}

Berdasarkan kerangka penelitian diatas maka terbentuk pengaruh antar masingmasing variabel yang akan dijelaskan dibawah ini:

\section{- Service Environment (SE) terhadap Service Quality (SQ)}

Persepsi dan perilaku dalam lingkungan tertentu adalah hasil emosional bagian keadaan yang diciptakan oleh lingkungan. Secara khusus ransangan lingkungan mempengaruhi emosi. Lingkungan layanan merupakan prediktor utama untuk evaluasi kualitas layanan Konseptualisasi awal lingkungan layanan dikembangkan untuk lingkungan offline tradisional (Tanuwijaya dam Ellyawati, 2016). Lingkungan layanan terdiri dari tiga dimensi unik: faktor ambien, faktor desain, dan faktor sosial (Tanuwijaya dam Ellyawati (2016). Faktor-faktor ini dianggap memiliki efek kritis pada evaluasi konsumen terhadap pengalaman ritel berdasarkan teori psikologi lingkungan dan lebih spesifik lagi, sistem pengelompokkan stimulus-organisme-respons (SOR).

Berdasarkan uraian tersebut, dugaan hipotesis yang diajukkan sebagai berikut:

H1: Pengaruh Service Environment terhadap Service Quality.

\section{- Customer Knowledge (CK) terhadap Service Quality (SQ)}

Pengetahuan konsumen berkaitan dengan aktivitas perilaku yang menciptakan pengetahuan berkaitan dengan kebutuhan konsumen sekarang maupun yang akan dating (Li dan Calantone, 1998 dalam Suliyanto, 2013). Proses pengetahuan konsumen berisi tiga aspek kegiatan yaitu memperoleh informasi, interpretasi dan integrasi.

Perusahaan harus hati-hati mengamati, berinteraksi dan menciptakan dialog dengan pelanggan mereka untuk mendapatkan pengetahuan pelanggan sehingga mereka dapat memberikan layanan yang disesuaikan dan memelihara hubungan jangka panjang. Kemudian, pengetahuan ini dapat memberi para distributor dan pengecer informasi untuk mengembangkan produk baru dan meningkatkan hubungan antara perusahaan dan pelanggan mereka. Dengan kata lain, perusahaan harus menggunakan pelanggan yang ada atau yang potensial.

H2: Pengaruh Customer Knowledge terhadap Service Quality 


\section{- Customer Relationship Management (CRM) terhadap Service Quality (SQ)}

Sistem CRM tidak hanya meningkatkan kemampuan organisasi untuk memulai, meningkatkan, dan mempertahankan hubungan dengan pelanggan, namun juga kemampuan untuk meningkatkan pengetahuan mereka tentang hal itu. Dengan kata lain, hubungan jangka panjang dengan pelanggan sebagian besar didasarkan pada pengetahuan pelanggan. Dengan akumulasi pengetahuan pelanggan, perusahaan dapat merencanakan dan melaksanakan CRM untuk memenuhi kebutuhan pelanggan yang tidak terpenuhi lebih baik daripada pesaingnya dan mempertahankan pelanggan yang paling berharga (Torkzadeh et al., 2006). Oleh karena itu, perusahaan yang memiliki pengetahuan lebih besar tentang pelanggan mereka cenderung meningkatkan kemampuan mereka untuk membangun hubungan pelanggan yang baik dan untuk meningkatkan kualitas layanan. Dengan kata lain, perusahaan dapat meningkatkan hubungan pelanggan melalui proses berbagi pengetahuan pelanggan sehingga staf juga dapat meningkatkan kreativitas mereka mengenai pengembangan produk baru dan kemampuan layanan yang ditingkatkan (Shi and Yip, 2007). Oleh karena itu, penelitian ini mengasumsikan bahwa CRM adalah variabel yang berorientasi pada proses dan bukan berorientasi pada hasil dan dapat memediasi hubungan antara pengetahuan pelanggan dan kualitas layanan.

H3: Pengaruh Customer Relationship Management terhadap Service Quality.

\section{- Service Quality (SQ) terhadap Brand Equity (BE)}

Efek pelayanan terhadap ekuitas merek saluran ritel. Penelitian mereka bertujuan untuk mengetahui pengaruh timbal balik kualitas layanan dan kualitas layanan elektronik terhadap ekuitas merek ritel serta efektivitas lingkungan layanan pada ekuitas merek ritel. Hasil penelitian menunjukkan bahwa persepsi konsumen akan kualitas layanan dan kualitas layanan elektronik berpengaruh positif terhadap ekuitas merek ritel.

H4: Pengaruh Service Quality terhadap Brand Equity.

\section{METODOLOGI PENELITIAN}

\section{Obyek Penelitian}

Obyek penelitian ini adalah private brand dengan merek yang dibuat sendiri oleh PT. XYZ dan subyek penelitiannya adalah konsumen dari PT. XYZ. Subyek yang dipilih konsumen yang datang ke outlet PT. XYZ yang sudah ditentukan untuk mengetahui apakah mereka mengenal brand diantara produk - produk nasional yang dijual di outlet PT. XYZ.

\section{Tempat dan Waktu Penelitian}

Pengambilan data responden dilakukan di outlet PT. XYZ yang berada di Jakarta yaitu di outlet Daan Mogot. Tidak hanya pengambilan data responden tetapi juga melakukan pengujian kuesioner untuk diuji validitas dan reliabilitas data dengan mengambil contoh responden pengunjung. Kegiatan pengumpulan data dilakukan pada bulan Mei 2017 Februari 2018.

\section{Jenis dan Sumber Data Penelitian}

Jenis dan sumber data yang digunakan dalam penelitian ini adalah data primer dan sekunder. Data primer adalah data yang diperoleh melalui wawancara dengan pengunjung outlet PT. XYZ menggunakan kuesioner. Pertanyaan dalam kuesioner terdiri dari data demografi dan kebiasaan belanja responden di outlet serta berkaitan dengan brand equity yang terdiri dari brand awareness, brand association dan perceived quality dan brand loyalty. Data sekunder adalah data yang diperoleh dari sumber studi literature yang relevan dengan nama penelitian, seperti jurnal, karya ilmiah, arsip perusahaan, dan lain - lain. 
Adapun tiga teknik pengumpulan data yang biasa digunakan adalah angket, observasi dan wawancara.

\section{Variabel Penelitian dan Operasionalisasi Variabel}

Pemilihan variabel merupakan variabel-variabel penelitian yang telah diteliti oleh penelititerdahulu dan disajikan variabel operasionalisasi variabel dalam tabel sebagai berikut:

Tabel 1. Definisi Konseptual dan Definisi Operasional

\begin{tabular}{|c|c|c|c|}
\hline Variabel & $\begin{array}{c}\text { Definisi } \\
\text { Konseptual }\end{array}$ & Definisi Operasional & Sumber \\
\hline $\begin{array}{l}\text { Customer } \\
\text { Knowledge }\end{array}$ & $\begin{array}{l}\text { Proses untuk } \\
\text { menangkap, } \\
\text { berbagi, } \\
\text { menerapkan data, } \\
\text { informasi dan } \\
\text { knowledge yang } \\
\text { berhubungan } \\
\text { dengan konsumen } \\
\text { untuk manfaat } \\
\text { perusahaan } \\
\text { (Wilde, 2011:56) }\end{array}$ & $\begin{array}{l}\text { 1. Tuntunan pelanggan yang terjadi } \\
\text { dipenuhi oleh kinerja pengiriman } \\
\text { fisik. } \\
\text { 2. Pesanan pelanggan secara efisien } \\
\text { ditangani secara efektif. } \\
\text { 3. Tenaga pemasaran mengerti produk } \\
\text { dan kondisi penggunaannya } \\
\text { 4. Karyawan mampu berkomunikasi } \\
\text { yang baik dengan pelanggan. } \\
\text { 5. Tanggung jawab terhadap pelanggan, } \\
\text { dan masalah lingkungan. }\end{array}$ & $\begin{array}{l}\text { Wayland } \\
\text { and Cole } \\
\text { (1997), }\end{array}$ \\
\hline $\begin{array}{l}\text { Customer } \\
\text { Relationship } \\
\text { Management }\end{array}$ & $\begin{array}{lr}\text { prosedur } & \text { strategis } \\
\text { holistik } & \text { yang } \\
\text { mencakup } & \\
\text { Akuisisi pelanggan, } & \text { seleksi, retensi dan } \\
\text { kolaborasi untuk } & \\
\text { mendukung } & \text { selektif } \\
\text { Retensi pelanggan } \\
\text { dan } \\
\text { mengelola } \\
\text { hubungan } \\
\text { pelanggan agar bisa } \\
\text { meningkat } \\
\text { Loyalitas pelanggan } \\
\text { dan profitabilitas } \\
\text { (Kandell, } \\
\text { Parvatiyar 2000; } \\
\text { Sheth, 2001; } \\
\text { 2001) Swift, }\end{array}$ & $\begin{array}{l}\text { 1. Infomasi dasar pelanggan yang } \\
\text { digunakan untuk segmen dan } \\
\text { mengklasifikan kebutuhan mereka. } \\
\text { 2. Perusahaan mampu menarik lebih } \\
\text { banyak pelanggan melalui penjualan } \\
\text { langsung dan pemasaran } \\
\text { 3. Kemampuan untuk mempertahankan } \\
\text { pelanggan dengan meningkatkan } \\
\text { kepuasan pelanggan sehingga mereka } \\
\text { mau membeli kembali. } \\
\text { 4. Mentransfer layanan pelanggan untuk } \\
\text { meningkatkan keuntungan } \\
\text { perusahaan dan ijinkan pelanggan } \\
\text { yang puas untuk merekomendasikan } \\
\text { produk }\end{array}$ & $\begin{array}{l}\text { Holmlund } \\
\text { and Kock } \\
\text { (1996), }\end{array}$ \\
\hline $\begin{array}{l}\text { Service } \\
\text { Quality }\end{array}$ & $\begin{array}{lr}\text { Kualitas } & \text { pelayanan } \\
\text { harus diukur selama } \\
\text { proses pemberian } \\
\text { layanan r dan } \\
\text { menyarankan agar } \\
\text { hal itu baisanya } \\
\text { terjadi r ketika }\end{array}$ & $\begin{array}{l}\text { 1. Penampilan Karyawan yang menarik, } \\
\text { fasilitas fisik dan pemasangan. } \\
\text { 2. Kemampuan yang dirasakan untuk } \\
\text { memberikan layanan memuaskan } \\
\text { 3. Kemampuan karyawan untuk } \\
\text { berinteraksi dengan pelanggan } \\
\text { memberikan respon dan pelayanan }\end{array}$ & $\begin{array}{l}\text { Parasura } \\
\text { man et al. } \\
(1985, \\
1988)\end{array}$ \\
\hline
\end{tabular}




\begin{tabular}{|c|c|c|c|}
\hline Variabel & $\begin{array}{c}\text { Definisi } \\
\text { Konseptual }\end{array}$ & Definisi Operasional & Sumber \\
\hline & $\begin{array}{l}\text { pelanggan dan } \\
\text { karyawannya } \\
\text { berada berurusan } \\
\text { dengan layanan. } \\
\text { (Sharabi dan } \\
\text { Davidow, 2010) }\end{array}$ & $\begin{array}{l}\text { yang cepat. } \\
\text { 4. Kompetensi dan kesopanan } \\
\text { karyawan, serta kemampuan untuk } \\
\text { menstimulasikan kepercayaan diri }\end{array}$ & \\
\hline $\begin{array}{l}\text { Service } \\
\text { Environment }\end{array}$ & & $\begin{array}{l}\text { 1. Kemampuan untuk memberikan jasa } \\
\text { yang dijanjikan dengan akurat dan } \\
\text { terpercaya } \\
\text { 2. kemampuan melaksanakan terus } \\
\text { secara spontan yang dapat menjamin } \\
\text { kinerja yang baik. } \\
\text { 3. Kebijakan untuk membantu dan } \\
\text { memberikan pelayanan yang cepat } \\
\text { kepada pelanggan } \\
\text { 4. Memberikan perhatian yang bersifat } \\
\text { individual dan pribadi kepada pelanggan }\end{array}$ & $\begin{array}{l}\text { (Parasura } \\
\text { manetal., } \\
\text { 1988: } 15)\end{array}$ \\
\hline Brand Equity & $\begin{array}{l}\text { Serangkaian aset } \\
\text { dan kewajiban } \\
\text { (liabilities) merek } \\
\text { yang terkait dengan } \\
\text { sebuah merek, nama } \\
\text { dan simbolnya, } \\
\text { yang menambah } \\
\text { atau men } \\
\text { mengurangi nilai } \\
\text { yang diberikan } \\
\text { sebuah produk atau } \\
\text { jasa kepada } \\
\text { perusahaan dan atau } \\
\text { pelanggan } \\
\text { perusahaan tersebut } \\
\text {.(Aaker, 1991) }\end{array}$ & $\begin{array}{l}\text { 1.Kemudahan mengingat kembali merek } \\
\text { 2. Merek yang paling diingat } \\
\text { 3. Pengenalan merek }\end{array}$ & $\begin{array}{l}\text { (Aaker, } \\
\text { 1991) }\end{array}$ \\
\hline
\end{tabular}

Sumber : data diolah peneliti, 2017

\section{Populasi dan Sampel}

populasi yang digunakan dalam melakukan penelitian ini merupakan responden konsumen di salah satu outlet PT. XYZ di Jakarta. Penelitian ini menggunakan teknik Probability sampling dengan kriteria sampel yang digunakan adalah responden dari konsumen. Karena jumlah populasi dalam penelitian tidak diketahui, maka jumlah sampel yang digunakan dalam penelitian ini sebanyak 100 - 150 responden dimana jumlah responden ini didapatkan jumlah indikator yang ada pada kuesioner penelitian (Hair et.al 2016, p.102).

\section{Metode Analisis}


Penelitian ini merupakan jenis analisis Structure Equation Model (SEM). Structural Equation Modeling (SEM) merupakan gabungan dari dua metodologi disiplin ilmu yang memfokuskan pada prediksi dan mampu untuk menggambarkan konsep model dengan variabel laten (variabel yang dapat diukur secara langsung) akan tetapi diukur melalui indikator-indikatornya (manifest variable). SEM secara esensial menawarkan kemampuan untuk melakukan analisis jalur (path analytic) dengan variabel laten (Chin, 1998; dalam Latan dan Ghozali, 2012. Hal 3). Untuk itu, program alat bantu statistik yang digunakan dalam penelitian ini merupakan $A M O S$ versi 18.

Pengambilan keputusan dilakukan dengan membandingkan nilai signifikansi di output $A M O S$ pada tabel Output Model Struktural dengan kriteria sebagai berikut:

$C . R \geq 1,96$ atau $\mathrm{P}$ value $<0,05=\mathrm{H}_{0}$ ditolak

C. $R<1,96$ atau $\mathrm{P}$ value $>0,05=\mathrm{H}_{0}$ tidak ditolak

\section{HASIL DAN PEMBAHASAN}

\section{Kecocokan Model Keseluruhan}

Analisa model struktural dalam SEM diawali dengan pengujian kecocokan model keseluruhan yang dilihat berdasarkan indikator Goodness-of-fitIndex (GFI) statistik dari output AMOS (Hair et al., 2016). Secara keseluruhan ringkasan nilai kritis dari pengujian kecocokan keseluruhan model dapat dilihat dari rangkuman dalam Tabel 2.

Tabel 2 Hasil Uji Kecocokan Model

\begin{tabular}{|c|c|c|c|}
\hline Kriteria & $\begin{array}{c}\text { Hasil } \\
\text { Model }\end{array}$ & $\begin{array}{c}\text { Tingkat kecocokan yang bisa } \\
\text { diterima }\end{array}$ & Evaluasi \\
\hline Chi-square & 128,547 & $\begin{array}{c}\leq 129,56, \text { dimana Chi Square } \\
\text { untuk df } 150 ; \text { Taraf Sig 5\% } \\
129,56\end{array}$ & Fit \\
\hline CMIN/DF & 3,184 & Antara $2-5$ & Fit \\
\hline GFI & 0,957 & $>0,90$ & Fit \\
\hline AGFI & 0,992 & $>0,90$ & Fit \\
\hline IFI & 0,902 & $>0,90$ & Fit \\
\hline TLI & 0,909 & $>0,90$ & Fit \\
\hline NFI & 0,915 & $>0,90$ & Fit \\
\hline CFI & 0,893 & $>0,90$ & Fit \\
\hline RMSEA & 0,072 & $<0,08$ & \\
\hline
\end{tabular}

Nilai CMIN/DF sebesar 3,184 menunjukan bahwa model structural di atas baik karena berkisar antara 2 sampai dengan 5 (March and Hocevar, 1985).nilai Goodness of fit index(GFI), Adjusted Goodness of Fit Index (AGFI), IFI, TLI, NFI, dan CFI dengan nilai mendekati 1 menunjukkan bahwa model baik. Sementara itu, nilai RMSEA sebesar 0,721 dapat dipertimbangkan model cukup baik. Menurut Hair et al. (2016) disarankan RMSEA bernilai antara 0,03 sampai 0,08 .

\section{Pengujian Hipotesis}

Berdasarkan hasil pengujian maka didapat structural equation modeling dengan pengujian dari variabel Service Environment, Customer Knowledge, dan Customer Relationship Management terhadap Service Quality dan dampaknya pada Brand Equity, seperti terlihat pada Gambar 2 berikut ini. 


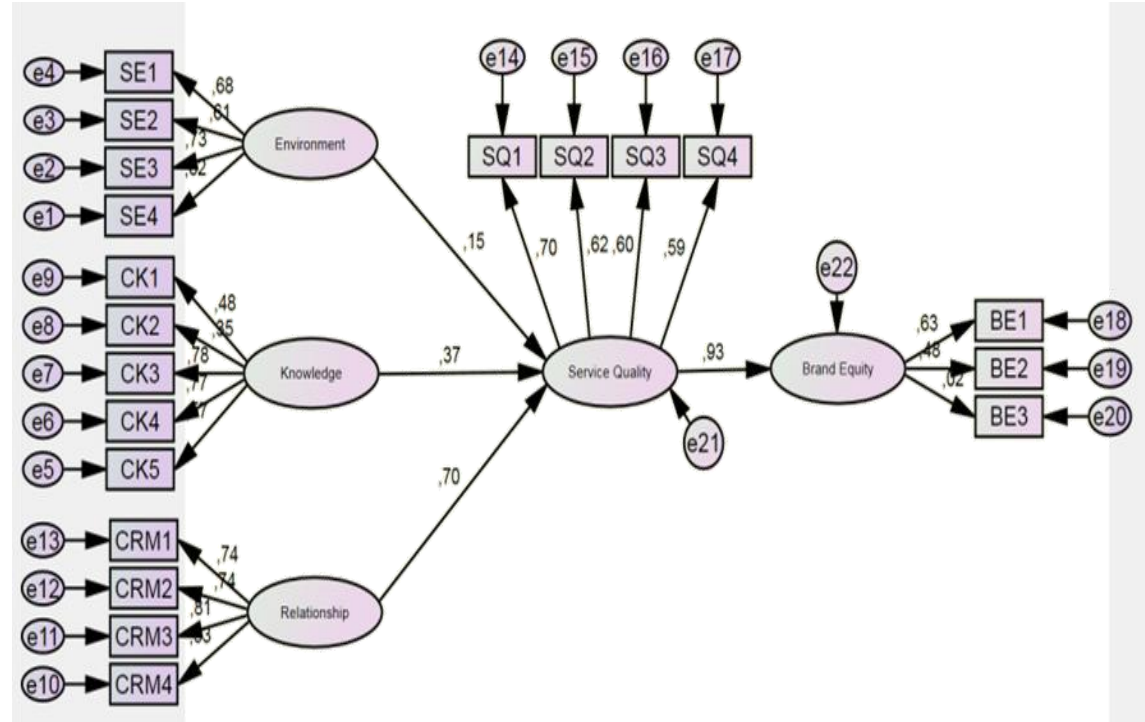

\section{Gambar 2. Model Penelitian Hasil Analisis}

Berdasarkan gambar di atas, selanjutnya dapat dilakukan analisis hipotesis yang dilakukan dengan melihat nilai C.R. (critical ratio) yang terdapat pada tabel output AMOS mengenai regression weights yang ditunjukkan pada tabel 3 berikut ini.

Tabel 3. Pengujian Hipotesis (Regression Weights)

\begin{tabular}{|ll|ccc|}
\hline \multicolumn{2}{|c|}{ Hubungan Variabel } & Estimate & C.R. & P \\
\hline Environment & $\rightarrow$ Service Quality & 0,146 & 1,760 & 0,078 \\
Knowledge & $\rightarrow$ Service Quality & 0,398 & 3,791 & 0.000 \\
Relationship $\rightarrow$ Service Quality & 0,758 & 5,052 & 0.000 \\
Service & $\rightarrow$ Brand Equity & 0,860 & 6,086 & 0.000 \\
Quality & & & \\
\hline
\end{tabular}

Berdasarkan data yang ditampilkan pada Gambar 4.1 dan Tabel 4.8 di atas, maka analisa terhadap hasil dari penelitian dapat dilakukan. Berikut adalah pembahsan setiap uji hipotesis berdasarkan hasil pengujian yang dirangkum pada tabel 4.8.

H1 = Service Environment $(\mathrm{SE})$ terhadap Service Quality (SQ)

Berdasarkan nilai pada Tabel 3 di atas, diketahui bahwa nilai Estimate yang diperoleh bernilai positif sebesar 0,146. Hasil tersebut menunjukkan bahwa apabila variabel Service Environment mengalami peningkatan sebesar satuan maka Service Quality juga akan mengalami peningkatan sebesar 0,146 (14,6\%). Namun, dilihat dari nilai CR pada variabel Service Environment sebesar 1,760 dan P-value sebesar 0,078. Nilai CR tersebut lebih kecil dari 1,960 dan P-value lebih besar dari 0,05. Oleh karena itu Ho1 diterima dan Ha1 ditolak artinya Service Environment tidak berpengaruh signifikan terhadap Service Quality. Dengan demikian dapat disimpulkan bahwa Service Environment memiliki hubungan positif namun tidak berpengaruh signifikan terhadap Service Quality.

\section{H2 = Customer Knowledge (SE) terhadap Service Quality (SQ)}

Berdasarkan nilai pada Tabel 3 di atas, diketahui bahwa nilai Estimate yang diperoleh pada variabel Customer Knowledge bernilai positif sebesar 0,398. Hasil tersebut menunjukkan bahwa apabila variabel Customer Knowledge mengalami peningkatan sebesar satuan maka Service Quality juga akan mengalami peningkatan sebesar 0,398 (39,8\%). Sementara itu, nilai CR yang diperoleh sebesar 3,791 dan P-value sebesar 0,000. Nilai CR tersebut lebih besar dari 1,960 dan P-value lebih besar dari 0,05. Oleh karena itu Ho2 ditolak dan $\mathrm{Ha} 2$ diterima artinya Customer Knowledge berpengaruh signifikan terhadap Service 
Quality. Dengan demikian dapat disimpulkan bahwa Customer Knowledge terbukti berpengaruh signifikan positif terhadap Service Quality.

H3 = Customer Relationship Management (CRM) terhadap Service Quality (SQ)

Berdasarkan nilai pada Tabel 3 di atas, diketahui bahwa nilai Estimate yang diperoleh pada variabel Customer Relationship Management bernilai positif sebesar 0,758. Hasil tersebut menunjukkan bahwa apabila variabel Customer Relationship Management mengalami peningkatan sebesar satuan maka Service Quality juga akan mengalami peningkatan sebesar $0,758(75,8 \%)$. Sementara itu, nilai CR yang diperoleh sebesar 5,052 dan P-value sebesar 0,000. Nilai CR tersebut lebih besar dari 1,960 dan P-value lebih besar dari 0,05. Oleh karena itu Ho3 ditolak dan Ha3 diterima artinya Customer Relationship Management berpengaruh signifikan terhadap Service Quality. Dengan demikian dapat disimpulkan bahwa Customer Relationship Management terbukti berpengaruh signifikan positif terhadap Service Quality.

\section{H4 = Service Quality (SQ) terhadap Brand Equity (BE)}

Berdasarkan nilai pada Tabel 3 di atas, diketahui bahwa nilai Estimate yang diperoleh pada variabel Service Qulity bernilai positif sebesar 0,860. Hasil tersebut menunjukkan bahwa apabila variabel Service Quality mengalami peningkatan sebesar satuan maka Brand Equity juga akan mengalami peningkatan sebesar 0,860 (86\%). Sementara itu, nilai CR yang diperoleh sebesar 6,086 dan P-value sebesar 0,000. Nilai CR tersebut lebih besar dari 1,960 dan P-value lebih besar dari 0,05. Oleh karena itu Ho4 ditolak dan Ha4 diterima artinya Service Quality berpengaruh signifikan terhadap Brand Equity. Dengan demikian dapat disimpulkan bahwa Service Quality berpengaruh signifikan terhadap Brand Equity.

\section{Implikasi Manajerial}

Berdasarkan hasil penelitian menunjukkan bahwa Service Environment memiliki hubungan positif namun tidak berpengaruh signifikan terhadap Service Quality. Berdasarkan hasil tersebut, untuk meningkatkan Service Environment disarankan kepada pihak manajemen untuk memberikan pelayanan sesuai dengan janji yang diberikan dan dapat dipercaya, memberikan kinerja terbaik kepada pelanggan dengan memberikan perhatian secara personal kepada pelanggan, dan memberikan respon yang cepat kepada pelanggan dalam setiap permasalahan yang dihadapi.

Customer Knowledge terbukti berpengaruh signifikan positif terhadap Service Quality. Berdasarkan hasil tersebut, untuk meningkatkan Customer Knowledge disarankan kepada pihak manajemen dan karyawan untuk terus menjaga hubungan baik dengan pelanggan seperti bertanggung jawab penuh atas pelanggan dan masalah lingkungan, berkomunikasi dengan baik terhadap pelanggan dalam menyampaikan informasi produk secara jelas, serta memenuhi permintaan pelanggan dengan adanya kinerja pengiriman fisik yang efektif dan efisien.

Customer Relationship Management terbukti berpengaruh signifikan positif terhadap Service Quality. Berdsarkan hasil tersebut untuk meningkatkan Customer Relationship Management, disarankan kepada pihak manajemen dan karyawan untuk terus melakukan inovasi produk, serta meningkatkan penjualan secara langsung, memberikan pelayanan yang maksimal untuk meningkatkan kepuasan pelanggan, dan memanfaatkan rekomendasi pelanggan untuk mendapatkan pelanggan baru.

Service Quality berpengaruh signifikan terhadap Brand Equity. Berdasarkan hasil tersebut untuk meningkatkan Service Quality, disarankan kepada pihak manajmen untuk memperhatikan karyawan agar berpenampilan menarik, sopan dan terpercaya sehingga dapat memberikan pelayanan terbaik kepada pelanggan. 


\section{KESIMPULAN DAN SARAN}

Dengan memperhatikan analisis dan pembahasan yang telah dilakukan, dapat ditarik beberapa kesimpulan antara lain sebagai berikut:

- Service Environment memiliki hubungan positif namun tidak berpengaruh signifikan terhadap Service Quality.

- Customer Knowledge terbukti berpengaruh signifikan positif terhadap Service Quality.

- Customer Relationship Management terbukti berpengaruh signifikan positif terhadap Service Quality.

- Service Quality berpengaruh signifikan terhadap Brand Equity.

Berdasarkan kesimpulan di atas, terdapat beberapa saran sebagai berikut :

- Untuk Manajemen PT. XYZ di Jakarta, disarankan untuk terus mempertahankan kondisi lingkungan pelayanan yang sudah dirasakan dengan baik oleh konsumen PT. XYZ. Selain itu, meningkatkan kualitas pelayanan dengan memperhatikan pengetahuan pelanggan dan menjalin hubungan yang baik kepada pelanggan. Perusahaan juga diharapkan dapat terus meningkatkan kualitas pelayanan sehingga dapat berpengaruh terhadap ekuitas merek.

- Untuk penelitian selanjutnya, disarankan untuk menambahkan variabel lain dalam model sebagai faktor yang mempengaruhi kualitas pelayanan dan ekuitas merek. Selain itu, disarankan untuk memperluas sampel penelitian sehingga memperoleh hasil yang lebih akurat.

\section{DAFTAR PUSTAKA}

Aaker, David A. (1991). Managing Brand Equity: Capitalizing on The Value of a Brand Name. New York: The Free Press.

Abdis, Fitri Yadi., Hairudinor., dan Hidayati, Noor. (2015). Pengaruh Attitude, Knowledge dan Penerapan CRM terhadap Kinerja Customer Service Bank BNI Area Kalimantan Selatan. Jurnal Bisnis dan Pembangunan, Vol 3, No. 1.

Allegro, Natanael Christian. (2015). Private Label : Kajian Persepsi Kosumen akan Kualitas dan Value For Money. Jurnal Studi Manajemen, Vol. 9, No. 2.

Angkow, Febrian., Sepang, Jantje L., dan Sumarauw, Jacky S B. (2016). Pengaruh Servicescape dan Kualitas Pelayanan Customer Service Terhadap Kepuasan Nasabah pada Pt. Bank Bni (Persero, Tbk) Cabang Manado. Jurnal Berkala Ilmiah Efisiensi, Vol. 16, No. 04.

Gibbert, M., Leibold, M., \& Probst, G. (2002). Five styles of customer knowledge management and how smart companies use then to create value. European Management Journal, 20(5), 459-469. https://doi.org/10.1016/S0263-2373(02)001019.

Hair, J. F., Black, W. C., Babin, B. J., dan Anderson, R. E. (2016). Multivariate Data Analysis: A Global Perspective (7th ed.). New Jersey: Pearson Education, Inc.

Hartono, Hendry., Hutomo, Karyana., dan Mayangsari, Marshelia. (2012). Pengaruh Strategi Pemasaran Terhadap Peningkatan Penjualan pada Perusahaan dengan Menetapkan Alumni dan Mahasiswa Universitas Bina Nusantara sebagai Objek Penelitian. Jurnal BINUS Business Review, Vol. 3, No. 2.

Holmlund, Maria., dan Soren, Kock. (1996). Relationship marketing: The importance of customer-perceived service quality in retail banking. The Service Industries Journal, Vol. 16, No. 3pp. 287.

Iskandar, Boston., dan Sugiharto, Sigiono. (2013). Analisa Pengaruh Faktor-faktor Service Quality Terhadap Customer Satisfaction di Restoran Mr. Pancake Surabaya. Jurnal Manajemen Pemasaran, Vol. 1, No. 1.

Kotler, Phillip. (2009). Manajemen Pemasaran, Edisi 13. Jakarta: Erlangga. 
Majid, Mohamadi Zahra, Rajabi Azade. (2016). Effect Of Dimensions Of Service Quality On The Brand Equity In The Fast Food Industry. DOI 10.1515/sbe-2016-0033

Marliana (2018). Ritel Pemasaran https://malianariska26.wordpress.com/manajemen-strategiuntuk-pemasaran-ritel/

Marshellina., dan Prabowo, Hartiwi. (2013). Pengaruh E-Crm dan Service Quality Terhadap Customer Satisfaction dan Dampaknya Terhadap Customer Loyalty pada Pt Xl. Jurnal Binus Business Review, Vol.4, No. 2.

Nazeri, Payam., and Tajdin, Ali. (2017). The Impact of Customer Knowledge and Customer Relationship Management in the Quality of Services in the Insurance Company Sarmad. Research in Economics and Management, Vo. 2, No. 4.

Parasuraman. V., Zeithaml. A., and Berry L.L. (1985). Problems and Strategies in Servies Marketing. Jurnal of Marketting, Vol. 49.

Rahayu, Sri. (2011). Internal Customer Satisfaction and Service Quality Toward Trust and Word of Mouth. Asean Marketing Journal, Vol.3, No.2.

Sirait, Dodi Putra. (2018). Pengaruh Customer Relationship Management Dan Kualitas Pelayanan Terhadap Kepuasan Pelanggan. Jurnal Digest Marketing, Vol. 3 No.1.

Tanuwijaya, Sandra Dewi., dan Ellyawati, J. (2016). Pengaruh Karakteristik Lingkungan Toko Dan Perilaku Positif Emosional Konsumen Terhadap Perilaku Impulse Buying: Pengujian Efek Moderasi Faktor Situasional. Tanpa Judul Jurnal.

Tempo.com (2014). Tren Perkembangan Ritel, Pasar Tradisonal Akan Tergusur. https://bisnis.tempo.co/read/46731/tren-perkembangan-ritel-pasar-tradisonal-akantergusur

Torkzadeh, G., Doll, William J., dan Xia, Weidong. (2006). A Confirmatory Factor Analysis of The End-User Computing Satisfaction Instrument. Management Information System Quarterly, Vol. 18, No. 4, pp. 453-461.

Wayland, Robert E., dan Cole, Paul M. (1997). Customer Connection: New Strategies for

Growth. Boston: Harvard Business School Press. 
